\title{
The 1974 National Economic Plan: Riding Out the Storm
}

\author{
KEITH M. CARLSON
}

\section{T}

HE Administration recently presented to Congress and the public its national economic plan for the eighteen-month period ending June 30,1975 . The Administration's plan is contained in three documents - the Federal Budget, the Economic Report of the President, and the Annual Report of the Council of Economic Advisers. Included in the economic plan are: (1) a proposed program for the Federal budget; (2) goals for gross national product (GNP), output, prices, and employment; and (3) recommendations for monetary actions by the Federal Reserve System.

Goals for the U.S. economy in the months ahead are outlined in the Council of Economic Advisers' (CEA) Report and are conditioned by economic forces already in motion, as well as the expected impact of planned policy actions. Because of conditions existing at the beginning of the year, the CEA indicates that the idea of a "goal" is more relevant to the latter part of the year than to the months immediately ahead. The Administration's goals include: an 8 percent advance in GNP from calendar 1973 to 1974 (or about 7.5 percent from fourth quarter 1973 to fourth quarter 1974); an increase in output of 1 percent from 1973 to 1974 ; a rise in prices, as measured by the GNP deflator, of 7 percent; and a rise in unemployment to an average slightly above 5.5 percent of the labor force in 1974 .

Proposed as consistent with these economic projections for 1974 is a Federal budget program containing expenditure increases (on a national income accounts basis) of 15 percent from calendar 1973 to $1974 .^{1}$ Tax changes consist of an increase in the tax base for social security contributions and a proposed emergency windfall profits tax. The Administration indicates that

\footnotetext{
The Administration does not provide estimates for calendar 1974. Such estimates have been prepared by this Bank on the basis of fiscal year projections in the budget and actual data through fourth quarter 1973.
}

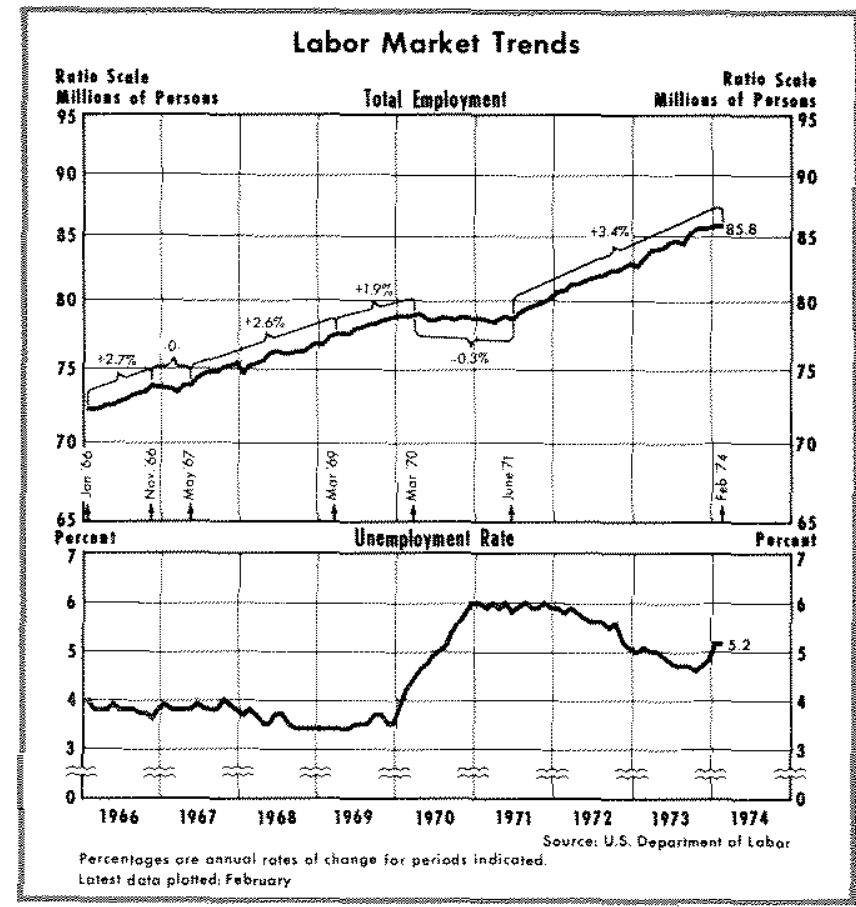

an 8 percent growth of the broadly measured money stock would be consistent with their economic projections for 1974.

This article summarizes and evaluates the Administration's 1974 economic plan. First, as background, the economic experience of 1973 is summarized in light of plans and projections made in January 1973. Second, the proposed Federal budget program is discussed in some detail, along with the CEA recommendation for monetary policy. Third, the economic plan for 1974 is evaluated in terms of its feasibility and internal consistency.

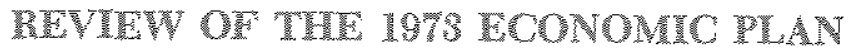

In late 1972 and early 1973 the U.S. economy was in the midst of a strong economic expansion. For the 
year ending fourth quarter 1972, output grew 7 percent and reported prices rose 3.3 percent. In early 1973 wage and price controls were in the process of being relaxed by the Administration. In general, the objective of Administration policy at that time was to slow the economy to a maximum sustainable growth of output. Furthermore, with proposed policies of moderate restraint, inflationary pressures were expected to subside by late in the year. However, the record of developments in 1973 is all too familiar; problems evolved which were not accurately foreseen by the Administration, or by anyone else for that matter.

\section{Economic Gouls vis. the Recond}

The CEA Report of a year ago projected an increase in GNP of 10 percent from 1972 to 1973 . The realized increase was 11.6 percent. In only one other year out of the last twelve has the CEA underestimated the rise in GNP by such an extent - in 1966 (see Table I). And, interestingly, 1966 was also a year racked by excess demand and inflation, though in retrospect, the severity of the problem at that time appears mild by comparison.

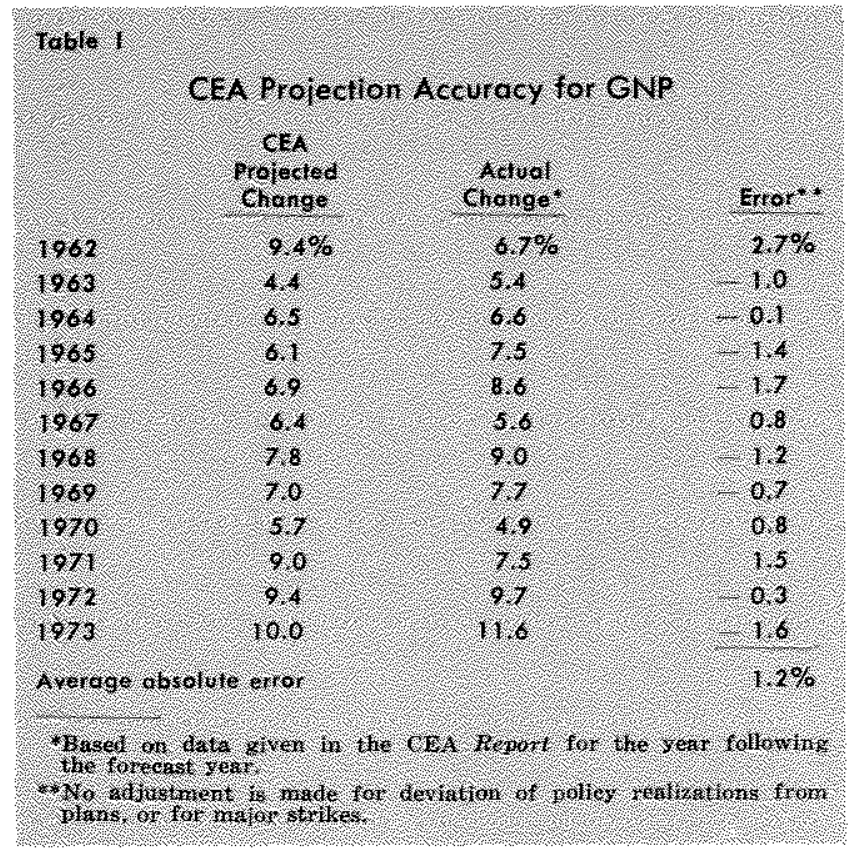

An examination of the 1973 projection of GNP according to its distribution between output and prices indicates that the error in projecting GNP was associated with an underestimate of the extent of price inflation (Table II). The CEA projected a 6.8 percent increase in output, compared to actual growth of 5.9 percent. Prices were projected to increase 3 percent, but actually rose 5.4 percent. The projection of

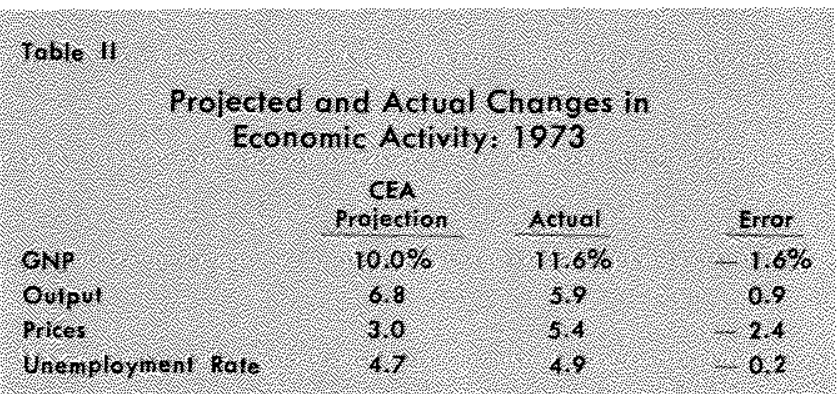

unemployment to average 4.7 percent of the labor force was close to the actual average of 4.9 percent.

The error in the 1973 GNP forecast is shown in greater detail in Table III. A large portion of the error in projecting total GNP took the form of an underestimate of the increase in personal consumption and a tumaround in the nation's net export position. These underestimates were offset partially by an overestimate of inventory accumulation.

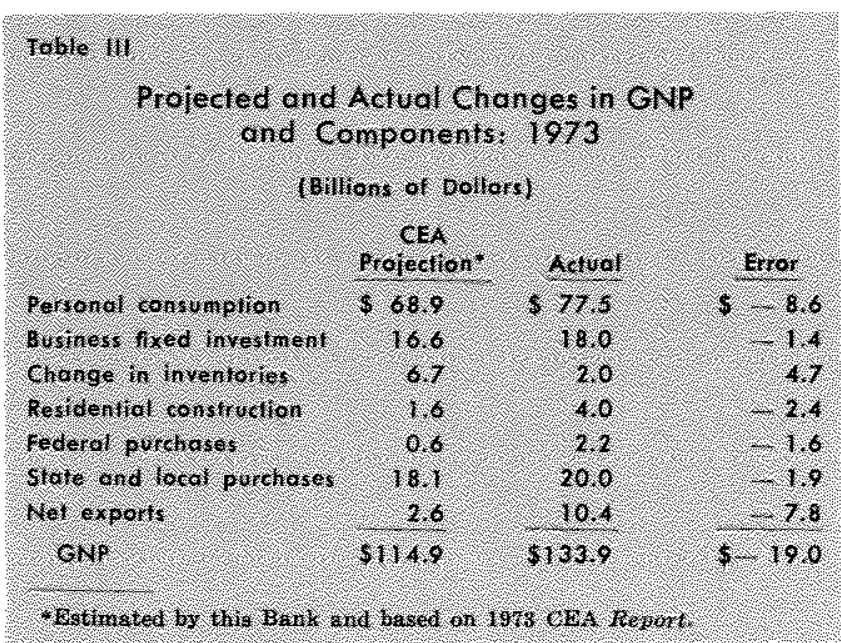

There were, of course, special factors which came into play during the year that contributed to the deviation of economic performance from the CEA's goals. Reference is made to the circumstances relating to agricultural prices, the energy situation, distortions built into the economic system by price and wage controls, and foreign exchange rates.

\section{Policy Plans vs. Realidations}

Normally, ex-post assessment of any economic plan depends on more than just a comparison of realized and projected values of GNP, prices, and output. A more complete evaluation also takes into account a comparison of policy plans with policy realizations. This section indicates that the error in projecting the major economic aggregates cannot be traced to sharp deviations of monetary and fiscal actions from original plans and recommendations. Significant projection er 
rors do raise the possibility that the economic impact of prior and current monetary and fiscal actions was miscalculated. It is difficult, however, to gauge the extent of this miscalculation, given special factors like reduced supplies of farm products and petroleum.

Federal budget plans are compared with the actual results in Table IV. Indications are that Federal expenditures were almost exactly on target in calendar 1973, while receipts were substantially underestimated. As a result, the NIA budget recorded a slight surplus during the year, or a decline in the deficit of $\$ 17$ billion, compared to a projected increase in the deficit of $\$ 4$ billion. The faster-than-expected rise in receipts is, of course, related to the underestimation of GNP and the pace of inflation. In particular, the unexpectedly rapid increase of corporate tax accruals contributed to a large underestimate of total Federal receipts.

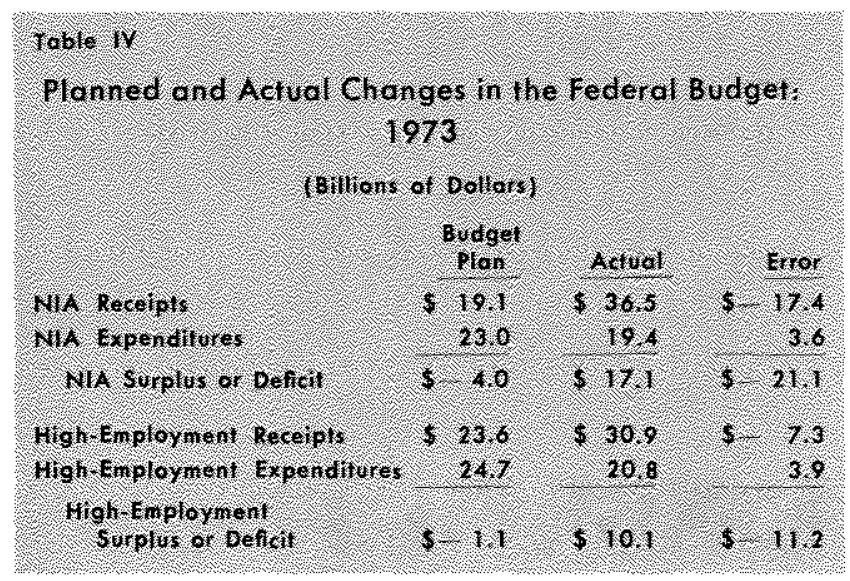

Planned and realized increases in receipts and expenditures, on a high-employment basis, are also shown in Table IV. Normally, an examination of highemployment budget plans provides a more meaningful basis of comparison of policy plans and realizations than does the NIA budget. However, during times of rapid inflation, the high-employment budget gives a distorted picture of the extent of fiscal stimulus or restraint. That is, according to Table IV, it would appear that there was more restraint than planned as evidenced by a surplus $\$ 11$ billion greater than planned in January 1973. High-employment receipts, and thus the net surplus or deficit, reflect inflation, and thereby suggest that the budget is showing more restraint than is actually the case. Some rough guesses can be made of the magnitude of the inflation bias, but there is no generally accepted method of making an inflation adjustment in the high-employment budget.

With regard to monetary actions as a part of the economic plan for 1973 , it is very difficult to deter-

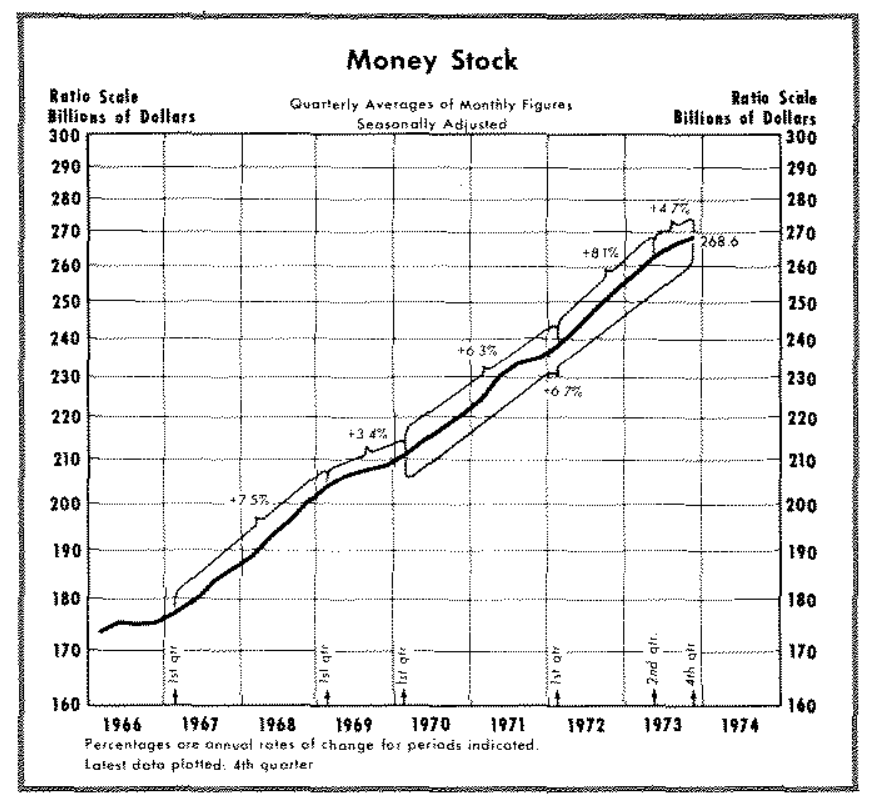

mine, in retrospect, whether monetary expansion during the year was consistent with the CEA recommendations in January 1973. In their 1973 Report, the CEA specified the role for monetary policy as follows:

A gradual slowing of the expansion of money GNP to a steady rate consistent with the long-run potential growth rate of the economy and reasonable price stability is also an appropriate goal for monetary policy. This is likely to require a slower increase of the supply of money and credit than was proper when the main objective was to encourage a quickened economic expansion in an environment of substantial unused resources. ${ }^{2}$

On the basis of recently revised figures for the money stock, it appears that, on average, the course of monetary expansion in 1973 was consistent with the CEA's general recommendation. Money grew 6.1 percent in the year ending fourth quarter 1973, compared to a 7.8 percent increase in the previous year. It should be pointed out, however, that this slowing in monetary growth occurred in the second half of the year. Given the lag with which monetary actions affect economic activity, the deceleration in money growth probably had little effect in slowing the growth of nominal GNP during the year. Money grew at a 7.4 percent annual rate in the first half of 1973, only slightly less than the 7.8 percent increase in the previous year.

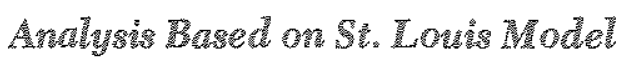

Substantial error in the CEA's GNP forecast, in the absence of any significant deviation of monetary-fiscal

21973 CEA Report, p. 75. 
policy realizations from plans, raises the possibility that there was a miscalculation of the impact of current and past policy actions on economic activity. To aid in the assessment of the CEA's 1973 economic plan, some simulation results with the $S t$. Louis model are presented.

Two after-the-fact projections of the St. Louis model are presented in Table V. The first projection uses money and high-employment expenditures as they were recorded in 1973. The second projection is the result of using money and high-employment expenditures consistent with the recommendations of the Administration in January 1973. The first projection, using actual movement in the policy variables, indicates that the St. Louis model projected the increase in GNP at $\$ 118$ billion, or $\$ 16$ billion less than actually occurred. The second projection indicates that move-

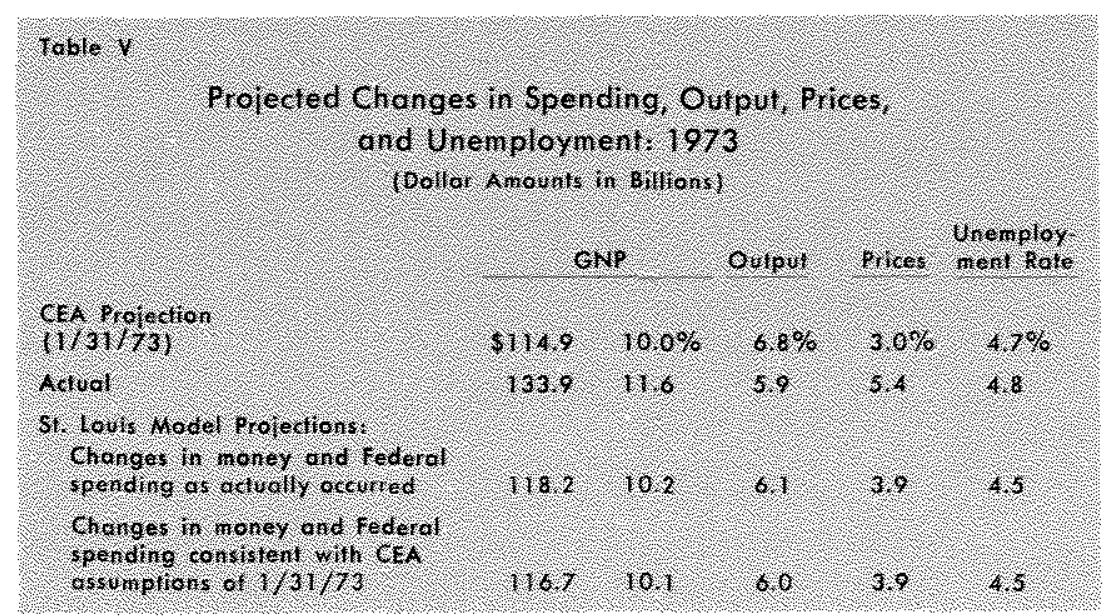

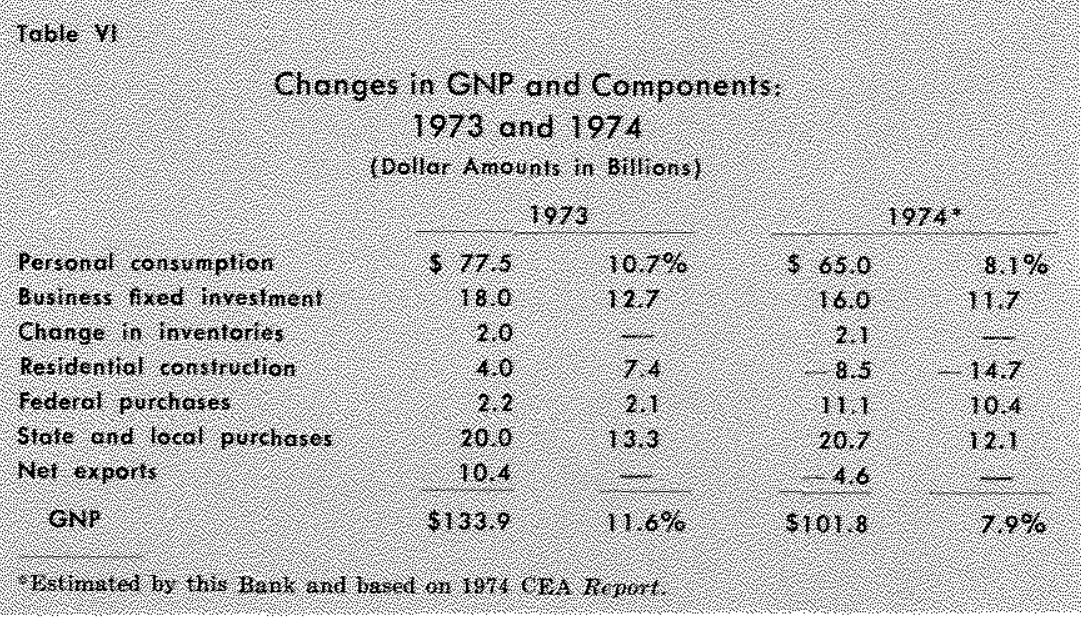

the energy problem and the scheduled dismantling of the system of price and wage controls. Monetary and fiscal actions seem to be assigned a secondary role in the assessment of the 1974 economic outlook.

The 1974 projections of the broad economic aggregates differ substantially from the actual experience in 1973. Furthermore, substantial differences are projected in the composition of GNP (Table VI). The most notable differences are with reference to personal consumption, residential construction, Federal purchases, and net exports. Personal consumption is projected to slow to an 8 percent increase, in contrast to a 10.7 percent rise in 1973 . Residential construction is expected to decline by about 15 percent, after increasing 7.4 percent in 1973. Federal purchases are projected to rise over 10 percent, compared to a 2.1 percent ments of the policy variables in line with Administration recommendations would have increased GNP by $\$ 117$ billion. Thus, to the extent that the impact of monetary and fiscal actions is accurately captured by the St. Louis model, the effect of policy error on GNP can be assessed as negligible. Within the framework of the St. Louis model, $\$ 16$ billion of the $\$ 19$ billion error in the CEA forecast reflects the operation of special factors on the income velocity of money.

\section{POLICY PLANS AND RECOMMENDATIONS FOR 1974}

The Administration's projections of a 1 percent rise in output and a 7 percent rate of inflation in 1974 reflect the expected adjustment of the economy to some special factors relating to uncertainties surrounding increase in 1973. The net export position is expected to decline from the substantial surplus registered in 1973.

\section{Federal Budget Program for Calendar 1974}

The budget plan for 1974 is to restrain the decline of the economy during 1974 but to injeot no fiscal stimulus to push the economy above its average rate of expansion. Consequently, the budget plan is designed as a middle-of-the-road policy, supposedly geared so as not to contribute further to either unemployment or inflation.

The purpose of this section is to present the quantitative details of the Federal budget program on an 
NIA basis for calendar $1974 .^{3}$ The budget on an NIA basis is considered by many analysts to be more accurate than the mified budget for evaluating the economic impact of fiscal actions. On a unified basis some misleading information can be emitted because of matters of timing in expenditures and receipts, as well as transactions in existing assets. A judgment is offered as to the possible accuracy of the Administration's assessment of the economic impact of its budget.

Expendintures - The budget program indicates a $\$ 41$ billion increase, or 15 percent, in Federal expenditures on an NIA basis for calendar 1974 (Table VII). This compares with an 8.2 percent advance in 1973 and a 7.7 percent average rate of increase from 1968 to 1972 . If realized, the 1974 increase in expenditures would be greater than 82 percent of all year-tomyear changes since 1947.

Defense spending is projected to increase in 1974 by 5.5 percent, compared to no change in 1973 and a 1.3 percent average annual rate of decline from 1968 to 1972. This planned increase in defense spending reflects an attempt to meet the higher costs of maintaining forces and stocks of equipment and supplies, as well as an effort to produce new weapons systems.

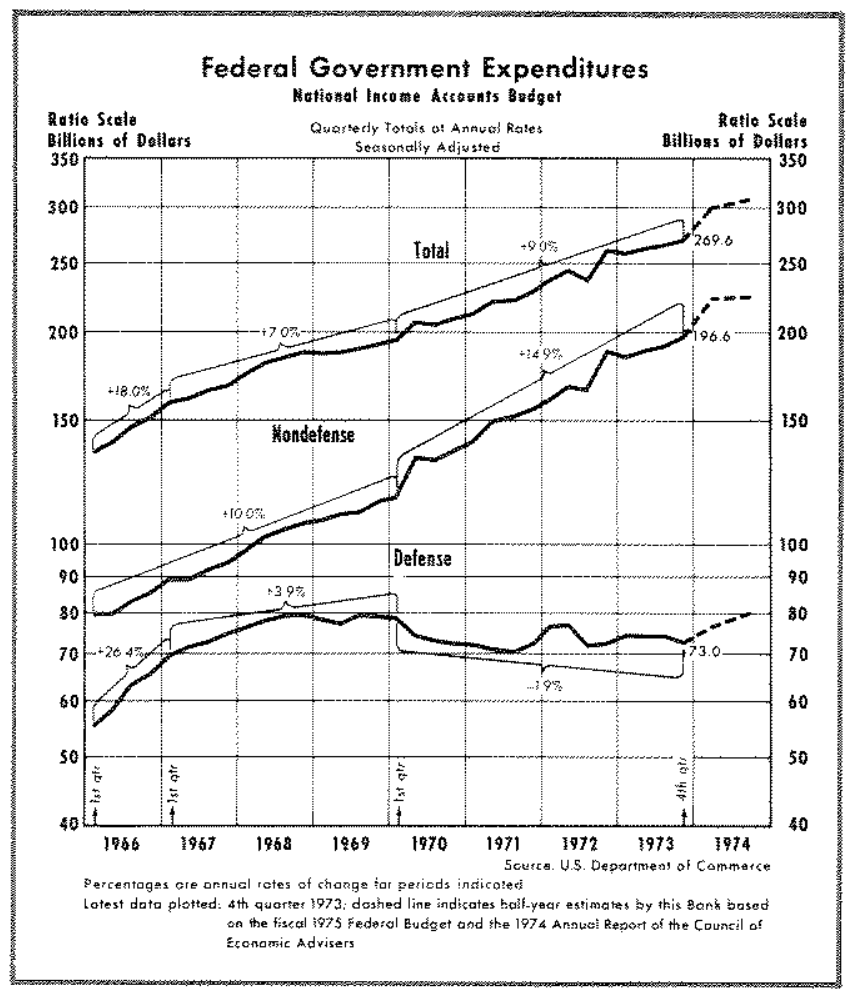

${ }^{3}$ As indicated above, all calendar year estimates for 1974 are prepared by this Bank. The chief basis for these estimates is Table C-68 in the $1974 \mathrm{CEA}$ Report, though fourth quarter 1973 figures have been revised since the Report was published.

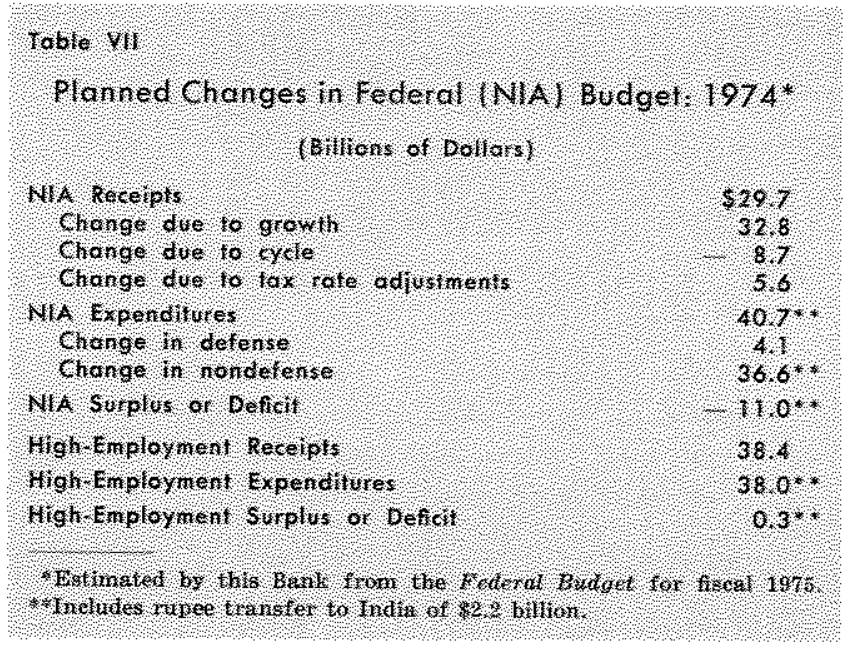

Nondefense spending, according to the Administration's budget, is projected to advance 19 percent in 1974, compared with 12 percent in the previous year and a 13 percent average rate of increase from 1965 to 1972. Within recent years there has been a dramatic shift in the size of nondefense spending relative to the total. The estimated proportion of Federal expenditures going toward nondefense purposes in 1974 is 74.3 percent, compared to 56.9 percent in 1968 .

Receipts - Federal receipts on an NIA basis are projected to rise by $\$ 30$ billion, or by 11 percent, in calendar 1974 . By comparison, receipts rose by 16 percent in 1973 and 15 percent in 1972 . These year-toyear comparisons require interpretation in light of changes in tax rates, as well as the advance of economic activity.

To aid in the interpretation of receipts projections, estimates of the sources of changes are given in Table VII. The receipts projection for 1974 reflects two major tax changes. Existing law calls for an increase in the tax base for social security contributions from $\$ 10,800$ to $\$ 13,200$, effective January 1,1974 . The only other major change is a proposed emergency windfall profits tax, although there is no indication in the budget as to when this new tax is expected to be effective. ${ }^{4}$ In addition, there are other minor proposed changes in tax laws which would have a negative effect on receipts - namely, liberalized deductions and tax structure simplifications.

Thus, given the estimated effect of changes in the tax strueture, the estimate of the rise in receipts attributable to the advance of economic activity (including both growth and cyclical factors) is estimated

4The calculations in Table VII were based on the assumption that the new tax would be fully effective by second guarter. 


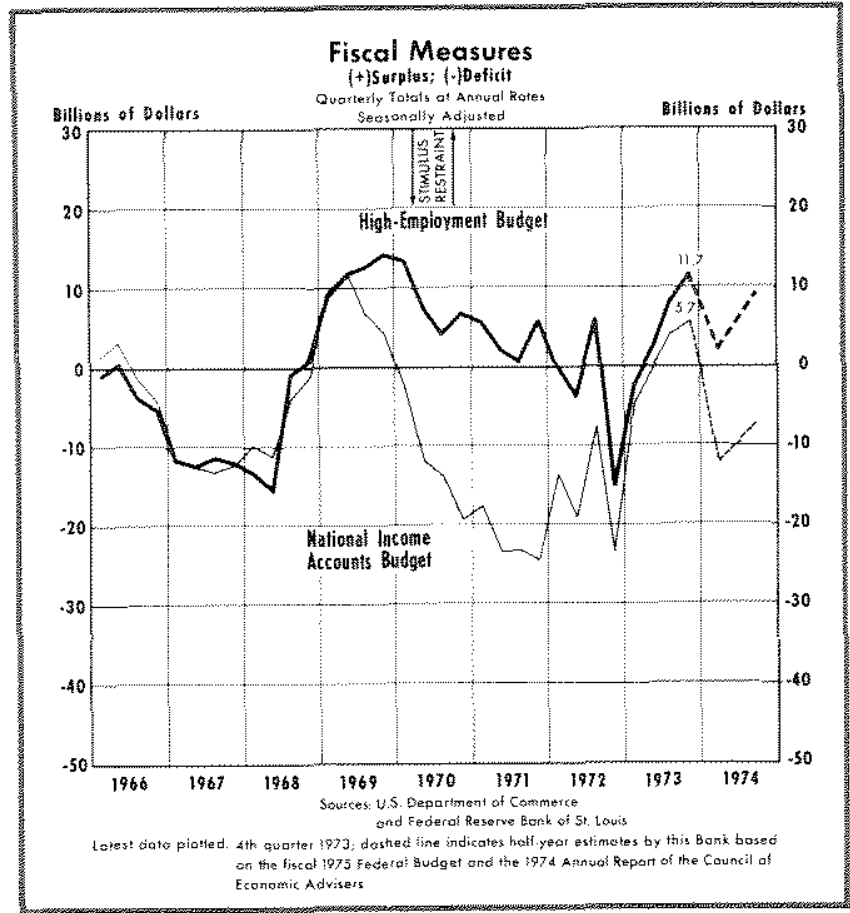

at $\$ 24$ billion. However, when allowance is made for the rise in receipts that could be expected from normal growth of the economy, it is apparent that cyclical forces are contributing to a decline in receipts in 1974.

Surplus/Deficit position - The combined effect of expenditures rising more rapidly than receipts results in a substantial shift in the net position of the NIA budget from a $\$ 1.2$ billion surplus in 1973 to a $\$ 9.8$ billion deficit in 1974. As indicated above, this shift toward deficit reflects a projected slowdown in economic activity, as well as changes in expenditure plans and tax laws.

The results of these calculations for the budget program for 1974 on a high-employment basis are given in Table VII. The high-employment budget is projected to show a surplus of about $\$ 5$ billion in 1974 , about the same as the estimated surplus in 1973 . Superficially, these figures indicate that the budget program is one of continuing restraint, but it should be recalled that these calculations are influenced in substantial measure by inflation. Thus the Administration's budget plan for calendar 1974 is more stimulative than indicated by the movement of the high-em ployment surplus.

\section{Monetary olicy wecommendathons for 1073}

The Administration's discussion of stabilization policy focuses on the Federal budget, with monetary policy receiving secondary emphasis. This emphasis tends to be dictated by the nature of the mandate of the Employment Act of 1946 and the way the CEA interprets its role in fulfiling the conditions of that legislation. For 1974, the CEA Report states its recommendation for monetary policy as follows:

The monetary expansion in the second half of 1973 can be described by ar increase in the narrowly defined money stock $\left(\mathrm{M}_{1}\right)$ of somewhat under 5 percent and an increase in the broadly defined money stock $\left(\mathrm{M}_{2}\right)$ of about 8 percent, at annual rates. Conm tinued growth in $\mathrm{M}_{2}$ at approximately this rate would be consistent with our expectations concerning the increase in GNP during 1974.5

Though the disctussion relating to this recommendation is limited, the precision of this recommendation represents a break with past tradition. Never before has the CEA given such a precise indication of its monetary policy recommendation. Usually such recommendations take the form of statements like "The role of monetary policy in the expansion ahead will be to provide for the increase of liquidity required to support increases in activity and income."

\section{EVALUATON OF 1974 WCONONIC PLAN}

According to the CEA, "the main functions of policy [in 1974] will be to keep the dip in the early part of the year from going too far and to assist the revival later in the year, but to avoid stimulating too rapid a surge." Clearly, the Council is fully aware of the uncertainties relating to the economic outlook, and wishes to keep its options open so that policy can be flexed in either direction, depending on the actual course of developments during the year.

In general, the special circumstances which are present in shaping the course of the economy in 1974 are quite unique. As a result, econometric models are less useful than otherwise in providing information about the probable course of economic events. Econometric models, by necessity, are structured on the basis of experience. However, despite their limitations, model results, particularly as they relate to the response of the economy to monetary and fiscal actions, should not be overlooked just because certain special circumstances seem to be so overwhelming in their implications. For this reason, it is still useful to conduct simulations for purposes of gaining insights into the expected effects of planned monetary and fiscal actions in 1974. These simulations have to be given a liberal interpretation but can still serve as a general

51974 CEA Report, pp. 31-32.

61972 CEA Report, p. 26. 
guide in the assessment of the Administration's economic plan.

This section evaluates the 1974 economic plan with the use of the St. Louis model. This is a policy-oriented model and is based solely on past experience. As a result, the St. Louris model does not lend itself to manipulation for purposes of analyzing energy problems or programs of price and wage control or decontrol. Given these qualifications, simulations of the St. Louis model are presented for purposes of determining (I) if the projected increase in total spending (GNP) by the Administration is consistent with the proposed set of monetary and fiscal actions, and (2) if the price and output projections are consistent with the forecast of total spending.

\section{Feasibility of Total Spending Projection}

The Administration's projection of an increase in GNP of $\$ 102$ billion, or 8 percent, is examined by considering two simulations of the St. Louis model. One simulation uses an 8 percent rate of steady growth in $\mathrm{M}_{2}$, and the other uses a 5 percent rate of growth in $\mathrm{M}_{1}{ }^{i}$

Both simulations use a path of high-employment Federal expenditures which is somewhat different than implied in the budget. Budget estimates imply an intra-year pattern for 1974 which consists of a substantial acceleration in spending in the first half of calendar 1974 followed by a sharp deceleration carrying through the first half of calendar 1975. A more likely path is used for simulation purposes which involves a gradual approach to a 10.7 percent annual rate of increase of expenditures by second quarter 1974. This path still implies a substantial pick-up in expenditure growth in the first half of 1974 , but the subsequent deceleration is much less marked than strictly implied by the budget plan. This deviation from the budget plan is premised on the recent budget experience of overestimating current (fiscal) year expenditures.

The results for these combinations of policies are shown in Table VIII. The two combinations of monetary and fiscal actions yield GNP results which are higher than the CEA projection. In other words, the

\footnotetext{
TSince the Administration is not specific in recommending a growth rate for $M_{1}$, the 3 percentage point spread between $M_{1}$ and $M_{2}$ growth experienced over the last two years is used to provide an estimate of $M_{\text {f }}$ growth.
}

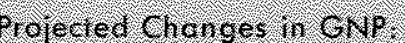

1974 and 1975

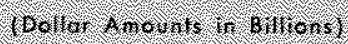

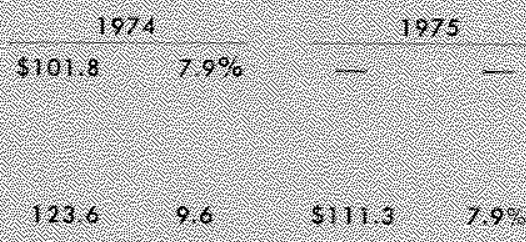

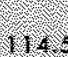

30

97.

7.6. when combined with policy plans for 1974, appear to be greater than foreseen by the Council. An interpretation is that the Council envisions a slower growth in velocity as a result of special factors relating to the energy problem and the program of price and wage decontrol. With little past experience to draw on, it is not possible to assess the validity of this interpretation. Nevertheless, the CEA projection appears to be within the range of error of the St. Louis model's GNP equation (though this judgment is questionable with regard to the results based on the $M_{2}$ equation), so there is no firm basis for considering the GNP projection to be inconsistent with the policies they recommend.

An implication of these results with the St. Louis model is that, at a minimum, monetary growth should be kept from exceeding the recommended rates in

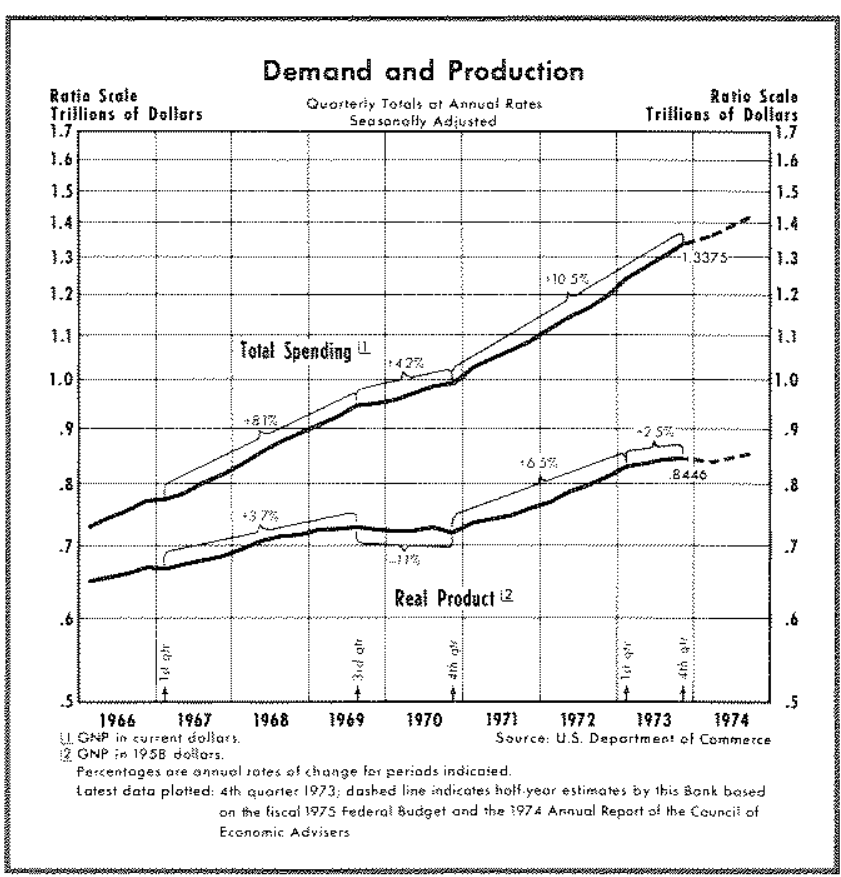




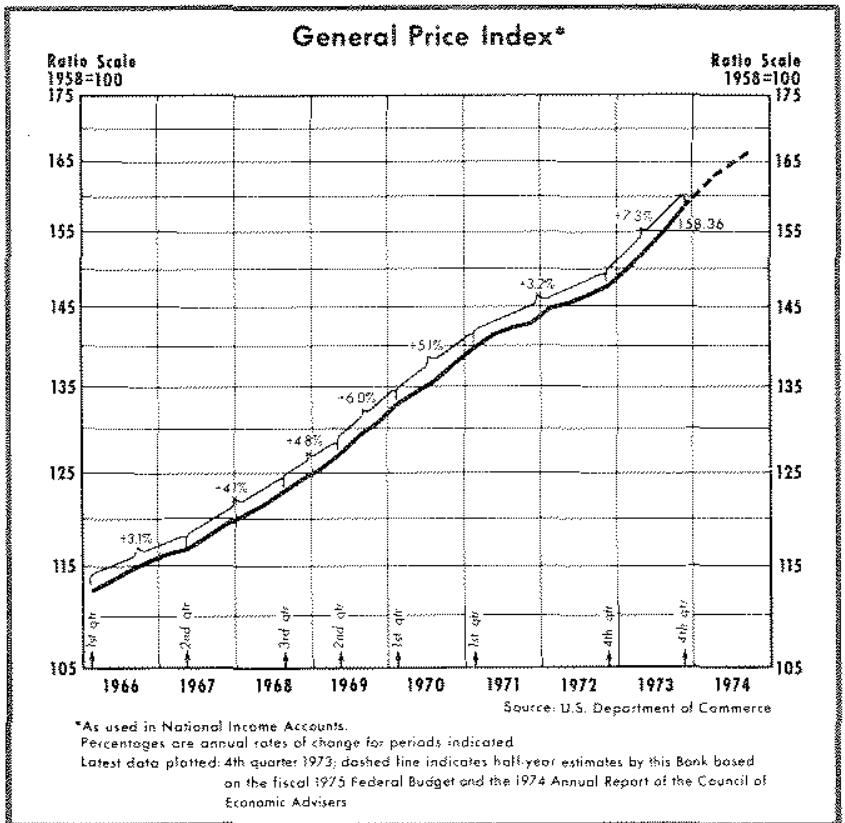

order to avoid a faster-than-desired increase in GNP. Given existing capacity constraints, a rise in GNP faster than projected would be reflected primarily in prices rather than in output.

\section{Implications of Total Spending Projections}

Given the feasibility of attaining the CEA's projection for GNP, the question remains whether the distribution of GNP growth between prices and output is consistent with the CEA projection. Examination of this question depends critically on what assumptions are made about the aggregate price effects of the energy problem, as well as the program of price and wage decontrol.

There have been some studies that have purported to measure the success of the price-wage control program, and thus carry implications about what the economie response might be to a program of decontrol. ${ }^{8}$ Closer examination indicates that such studies shed little, if any, light on the problem. For example, predicting what a price index would have done in the absence of controls and comparing that hypothetical result with what actually happened provides little insight because it is assumed that all of the effects of controls are reflected in a chosen price index. Since controls distort the operation of relative prices as an atlocative mechanism in a market economy, the effect of controls on an aggregate index is simply impossible to measure. Furthermore, there are output effects re-

8For a general discussion of pricemage controls in this context, see Robert Y. Gordon, "The Response of Wages and Prices to the First "Two Years," Brookings Papers on Economic Activity, 3 (1973), pp. $765-78$.

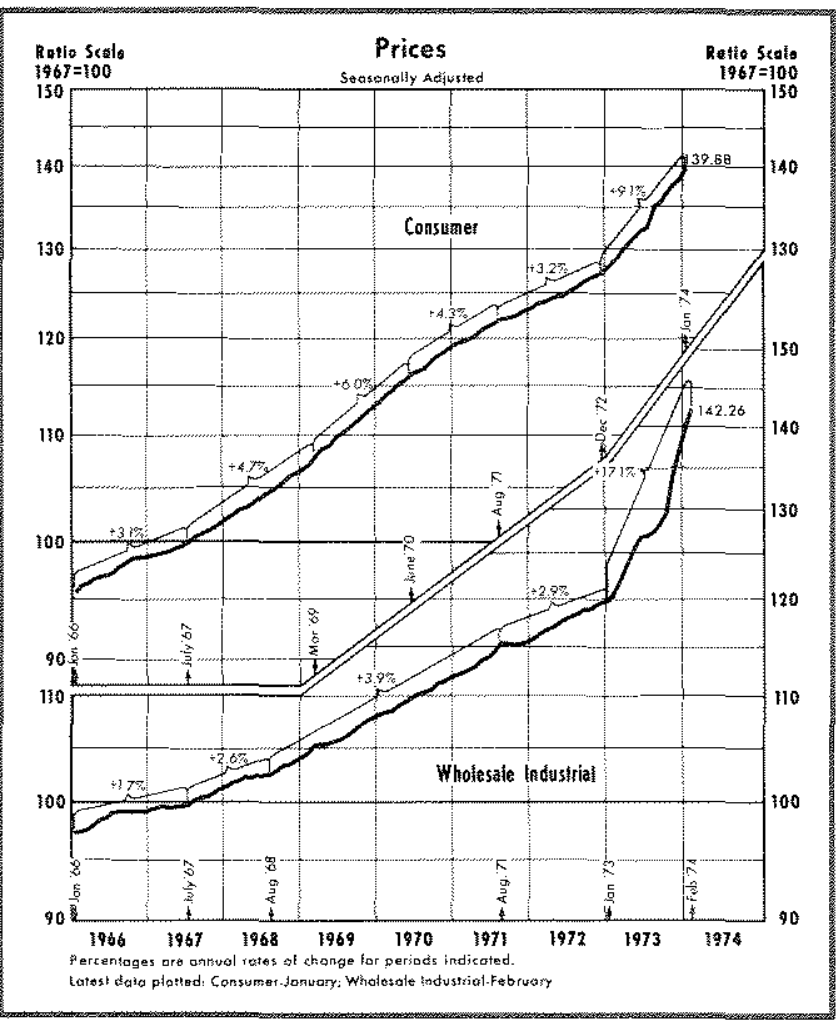

lated to a control program which affect the interpretation of a particular price index. In other words, the market basket is changing because of the control program which invalidates the price index as a measure of intertemporal price changes.

It appears that the most important aspect of the CEA's 1974 price and output projections is not so much whether or not they are likely to be realized, but rather the lessons they carry for the formulation of future monetary and fiscal policy. The relatively bleak 1974 outlook for prices and output shows the interdependence over time of economic policy decisions. The Administration, by becoming impatient in mid1971 with the pace of economic expansion and the rate of deceleration of inflation, adopted policies which formed the basis for an adjustment which appears to be developing in 1974 . Interference with the operation of free markets beginning in August 1971, followed shortly by stimulative monetary and fiscal actions, set the stage for the economic problems which began to surface in 1973.

Special circumstances undoubtedly play an important role in the analysis of current problems of inflation and capacity constraints. However, pointing to special circumstances as the chief cause of the current inflation demonstrates a lack of perspective. Instru. mental in the development of some of these special circumstances were the policies adopted in late 1971 
and the subsequent inordinate monetary and fiscal expansion. The demand for energy is not unrelated to the rapid pace of economic expansion and the 1971 policy emphasis on stimulating the automobile industry. Furthermore, the supply of energy is not unrelated to the administration of the program of price controls. Worldwide inflation would probably have been less rapid if the U.S. expansion and the associated demand for imports had been restrained. It is true that these policy actions cannot be undone, but such mistakes can be avoided in the future.

\section{SUMMARY}

The Administration has projected a year of rapid inflation and little growth in output, on balance. However, by focusing on the second half of calendar 1974 , the CEA projection turns more optimistic-a pick-up in output growth and a slower rate of inflation.

Offered as consistent with these projections is a Federal budget program which is allegedly neutral in its impact, but on closer inspection is more stimulative than in 1973. The Administration's monetary recommendations are couched in terms of an 8 percent growth rate in $\mathrm{M}_{\mathrm{g}}$, or slightly less than the growth in the previous year.
Using the St. Louis model as an aid in evaluating the 1974 economic plan, it was found that the CEA projection of GNP appears to be less than implied by the recommended 8 percent growth in $M_{2}$. Given the capacity constraints operating in the economy, underestimating the growth of GNP raises the specter of inflation in excess of the CEA's projection of 7 percent.

An accurate assessment of the Administration's projections for prices and output, given their GNP projection, is simply not possible given short-run considerations such as the energy situation and the scheduled program of price and wage decontrol. Aside from the question of whether the price and output projections are consistent with the projected GNP path is the more imporiant consideration that the developing economic situation be viewed in perspective so that similar situations can be avoided in the future. The interplay of "special circumstances" does inject some element of doubt over the future course of the economy. It should be noted, however, that the 1974 economic situation is not evolving independently of the inordinate monetary expansion of the previous two years and a price-wage control system that distorted the operation of a free market economy.

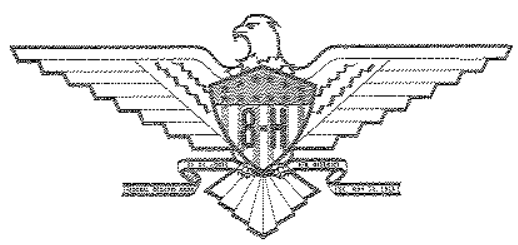

